\title{
Thermodynamic Performance Analysis of a CCHP System Fueled by Coke Oven Gas
}

\author{
H.B. Zhao, T. Jiang, W. Yang, Q. Yang \\ College of Mechanical and Transportation Engineering \\ China University of Petroleum \\ Beijing, China
}

\begin{abstract}
Inspiring from the idea of distributed energy utilization, using coke oven gas fed a combined cooling heating and power integrated system and aided by FORTRAN software to program and calculate the research system. The article concludes the influence of pressure and temperature ratios as well as the contents of $\mathrm{COG}$ such as $\mathrm{H}_{2}$ and $\mathrm{CH}_{4}$ on its thermal performance. Different parameters and the range of optimal operation parameter will provide guidance for the rational energy using and efficient operation of industrial power system.
\end{abstract}

Keywords-combined cooling heating and power system; coke oven gas; the pressure ratio; the temperature ratio; thermodynamic performance

\section{INTRODUCTION}

China is the first coke production country in the world. While outputting 1 ton coke in coking process, it produces $430 \mathrm{~m}^{3}$ coke oven gas (COG) [1]. Nevertheless, most of coke oven gas is diffused or open-flame burned. Only in Shan Xi Province, the waste burning of coke oven gas outnumbered 30 billion $\mathrm{m}^{3}$ per year which is more than double amounts of west-east gas transmission. In 2012, our country yield coke about 443 million tons while more than 1400 billion $\mathrm{m}^{3}$ coke oven gas is produced. Half of the gas is proceed to proper recycling and the other half is directly released or open-flame burnt.

Combined cooling, heating, and power (CCHP) [2-9] systems are integrated energy systems that produce electricity, cooling, and heating simultaneously, which is also referred to tri-generation. Using coke oven gas to fuel the tri-generation system is not only a saving of energy but also can supply energy for coking process.

The article aided by FORTRAN software, the corresponding models have been established and numerically calculated. From the results, we have concluded the influence of pressure and temperature ratios as well as the contents of COG such as $\mathrm{H}_{2}$ and $\mathrm{CH}_{4}$ on its thermal performance. Different parameters and the range of optimal operation parameter will provide guidance for the rational energy using and efficient operation of industrial power system.

\section{THE SYSTEM FLOW OF COG-CCHP}

The system layout is schematically shown in Fig.1. The system includes a gas turbine, a dual pressure heat recovery steam generator (HRSG), a back pressure style steam turbine [7-9], a single-effect Lithium Bromide-water (LiBr-H2O) absorption chiller and industrial cooling users and heating users. The main steams of the back pressure style steam turbine come from the high side superheated steam of the dual pressure waste heat boiler to generate more electricity. The heat source of the absorption chiller system comes from the low side of the heat recovery steam generator. The exhaust steam of the steam turbine is supplied for heat users and the whole cooling from the absorption chiller system is supplied for industrial cooling users.

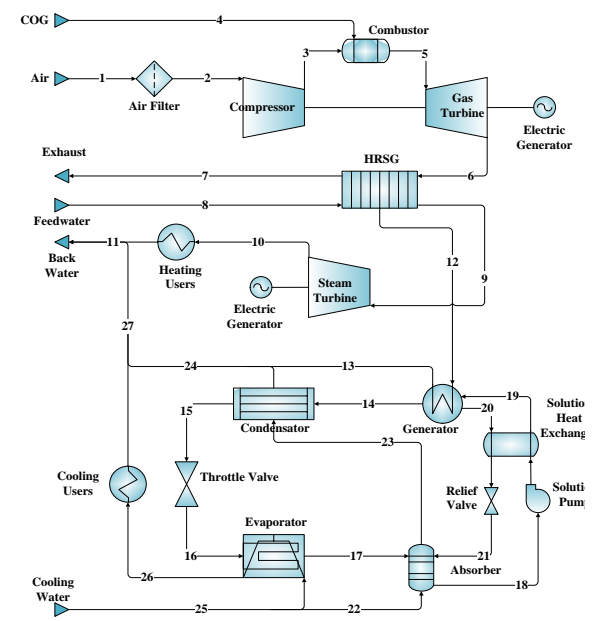

FIGURE I. THE LAYOUT OF COMBINED COOLING HEATING AND POWER SYSTEM FUELED BY COKE OVEN GAS.

\section{THERMODYNAMIC MATHEMATICAL MODELS OF COG-CCHP SYSTEM}

We have written programs and calculated them based on the actual needs and thermodynamic basic theory.

$$
\int_{T_{\text {in }}}^{T_{\text {out }}} C_{p} \frac{d T}{T}=R \cdot \ln \pi
$$

Eqn. (1) is the mathematical equation of compression consumption work and expansion work in a process of ideal reversible adiabatic condition. We used adiabatic efficiency to modify the power equipment to make up the irreversibility of the devices.

In the paper, assume the initial temperature of gas is known to calculate the fuel quantity.

$$
H_{\text {out }}=\left(H_{i n, a i r}+H_{i n, C O G}+L H V_{C O G}\right) \cdot \eta_{c}
$$


Eqn. (2) is the energy balance equation of combustor which considers the adiabatic efficiency $\eta_{c}$.

$$
\eta_{h}=\frac{P_{G T}+P_{S T}}{L H V_{C O G} \times m_{C O G}}
$$

Eqn. (3) is the] thermal efficiency of the integrated system.

$$
c=\frac{P_{t}-P_{c}}{P_{t}}
$$

Eqn. (4) is the useful work coefficient of the gas turbine. The useful work coefficient is equal to the percentage which is the ratio of delivery work and cycle expansion work. It can reflect the work ability of the working medium. Therefore, it`s usually as the effective index of performance evaluation.

TABLE I. THERMODYNAMIC PARAMETERS OF MAIN STATE POINTS.

\begin{tabular}{cccccc}
\hline $\begin{array}{c}\text { State } \\
\text { point }\end{array}$ & $\begin{array}{c}\text { Temperature } \\
{ }^{\circ} \mathrm{C}\end{array}$ & $\begin{array}{c}\text { Pressure } \\
\mathrm{MPa}\end{array}$ & $\begin{array}{c}\text { Mass } \\
\text { flow } \\
\mathrm{kg} / \mathrm{s}\end{array}$ & $\begin{array}{c}\text { Specific } \\
\text { enthalphy } \\
\mathrm{kJ} / \mathrm{kg}\end{array}$ & $\begin{array}{c}\text { Specific } \\
\text { entropy } \\
\mathrm{kJ} /(\mathrm{kg} \cdot \mathrm{K})\end{array}$ \\
\hline 1 & 15.0 & 0.100 & 21.60 & 2397.78 & 5.3388 \\
2 & 15.0 & 0.099 & 21.38 & 2397.78 & 5.3426 \\
3 & 326.2 & 1.164 & 21.38 & 2846.62 & 5.4764 \\
4 & 45.0 & 2.350 & 0.77 & 2785.10 & 8.9993 \\
5 & 1000.0 & 1.188 & 22.15 & 3936.79 & 6.7472 \\
6 & 467.0 & 0.094 & 22.15 & 3083.31 & 6.8377 \\
7 & 154.0 & 0.090 & 22.15 & 2610.86 & 6.0254 \\
8 & 104.0 & 5.250 & 2.80 & 439.80 & 1.3479 \\
9 & 466.6 & 3.938 & 2.40 & 3531.68 & 6.9973 \\
10 & 362.7 & 1.126 & 2.40 & 3182.81 & 7.2881 \\
11 & 180.0 & 1.014 & 2.40 & 763.06 & 2.1392 \\
12 & 50.0 & 0.012 & 0.40 & 2820.44 & 6.1129 \\
13 & 48.0 & 0.011 & 0.40 & 200.98 & 0.6778 \\
14 & 41.0 & $7.384(\mathrm{kPa})$ & 0.34 & 2575.47 & 8.2618 \\
15 & 39.0 & $7.384(\mathrm{kPa})$ & 0.34 & 163.36 & 0.5591 \\
16 & 6.6 & $1.002(\mathrm{kPa})$ & 0.34 & 163.40 & 0.0932 \\
17 & 8.0 & $1.002(\mathrm{kPa})$ & 0.34 & 2515.63 & 8.9809 \\
\hline
\end{tabular}

The pressure, temperature, mass flow, and composition of the main points in Fig.1 are listed in Table 1 when the CCHP system is operated at the design point.

Table 2 shows the main parameters by operation and calculation to prove the reliability of performance mathematical model in COG-CCHP system.
TABLE II. COMPARISON BETWEEN THE DATA OF OPERATION AND

\begin{tabular}{|c|c|c|c|c|c|}
\hline Item & Parameter & Unit & Operating & Calculatin & Relative \\
\hline \multirow{3}{*}{$\begin{array}{c}\text { fuel } \\
\text { System }\end{array}$} & Fuel flow & $\mathrm{kg} / \mathrm{s}$ & 0.78 & 0.76 & 0.0256 \\
\hline & Fuel pressure & $\mathrm{MPa}$ & 2.35 & 2.35 & 0 \\
\hline & Fuel temperature & ${ }^{\circ} \mathrm{C}$ & 45.00 & 45.00 & 0 \\
\hline \multirow{6}{*}{$\begin{array}{l}\text { Vapour } \\
\text { circulation } \\
\text { system }\end{array}$} & Main feed-water flow & $\mathrm{kg} / \mathrm{s}$ & 2.80 & 2.80 & 0 \\
\hline & Feed pressure & $\mathrm{MPa}$ & $5.25 / 1.40$ & $5.25 / 1.40$ & $0 / 0$ \\
\hline & $\begin{array}{c}\text { Superheated steam } \\
\text { flow }\end{array}$ & $\mathrm{kg} / \mathrm{s}$ & 2.40 & 2.3887 & 0.0047 \\
\hline & Saturated steam flow & $\mathrm{kg} / \mathrm{s}$ & 0.40 & 0.4113 & 0.0283 \\
\hline & $\begin{array}{c}\text { Back pressure steam } \\
\text { pressure }\end{array}$ & MPa & 0.9800 & 0.9817 & 0.0017 \\
\hline & $\begin{array}{c}\text { Back pressure steam } \\
\text { temperature }\end{array}$ & ${ }^{\circ} \mathrm{C}$ & 307.00 & 303.57 & 0.0112 \\
\hline \multirow{4}{*}{$\begin{array}{l}\text { Smoke } \\
\text { system }\end{array}$} & $\begin{array}{c}\text { Initial turbine } \\
\text { temperature in control } \\
\text { mode }\end{array}$ & ${ }^{\circ} \mathrm{C}$ & 1042.00 & & \multirow[t]{2}{*}{0.0403} \\
\hline & $\begin{array}{l}\text { Initial turbine } \\
\text { temperature }\end{array}$ & ${ }^{\circ} \mathrm{C}$ & & 1000.00 & \\
\hline & $\begin{array}{l}\text { Import smoke } \\
\text { temperature }\end{array}$ & ${ }^{\circ} \mathrm{C}$ & 473.00 & 467.06 & 0.0126 \\
\hline & $\begin{array}{c}\text { Export smoke } \\
\text { temperature }\end{array}$ & ${ }^{\circ} \mathrm{C}$ & 161.00 & 154.56 & 0.0400 \\
\hline Output & Gas turbine power & $\mathrm{kW}$ & 5504.00 & 5387.00 & 0.0213 \\
\hline parameters & Turbine power & $\mathrm{kW}$ & 3040.00 & 3000.19 & 0.0131 \\
\hline
\end{tabular}
CALCULATION OF MAIN PARAMETERS.

\section{THE PERFORMANCE ANALYSIS OF COG-CCHP SYSTEM IN VARIABLE CONDITION}

\section{A. The Effect of Different Pressure Ratios and Temperature Ratios on the System Performance}

Temperature ratio and compression ratio affect the gas turbine performance in a certain extent. With the change of temperature ratio and pressure ratio the sensitivity of performance has difference in unit.

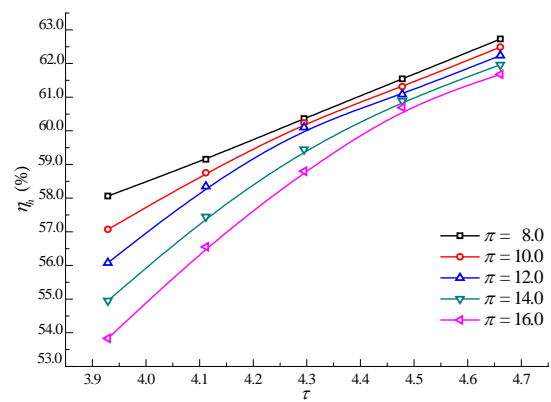

FIGURE II. $\eta h$ CHANGES WITH THE CHANGE OF $\tau$ AND $\pi$.

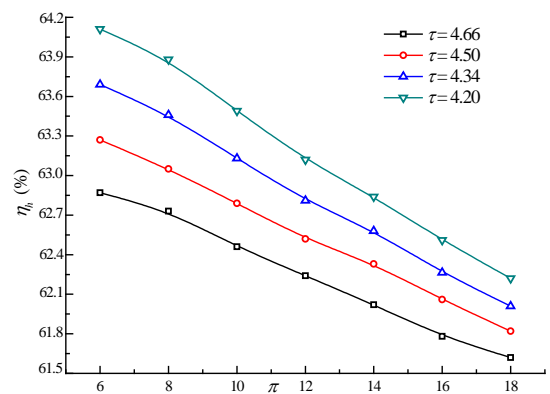

FIGURE III. $\quad \eta h$ CHANGES WITH THE CHANGE OF $\pi$ And $\tau$.

Fig.2 and fig.3 respectively show the effect of temperature 
ratios $\tau$ and pressure ratios $\pi$ on the efficiency of the whole system $\eta_{h}$ with several pressure ratios and several temperature ratios fixed. Assuming that the gas initial temperature TIT is $1000{ }^{\circ} \mathrm{C}$. With the increasing of the temperature ratio, the system thermal efficiency increases, on the contrary, the system efficiency decreases with the increasing of the pressure ratio. When the temperature ratio gains from 4.20 to 4.66 , the thermal efficiency increases from $57.5 \%$ to $61.5 \%$ with the pressure ratio fixed at 16.0 . However, when the pressure ratio changes from 6 to 18, the thermal efficiency decreases from $62.85 \%$ to $61.5 \%$ with the temperature ratio fixed at 4.20 .

\section{B. The Effect of Coke Oven Gas Contents on the System Performance}

This section analyzes the comprehensive effect of COG contents on the thermal performance of COG-CCHP integrated system. In the research, when we discuss the effect of different contents of COG on system performance, we let one of the components change, others are relatively constant to reflect the changing rules of the thermal performance.

Figure 4 shows the effect of hydrogen content in coke oven gas on the system performance. With the $\mathrm{H}_{2}$ content increasing, the low calorific value of coke oven gas and the output specific work of unit increase. The difference is that the increasing speed of low calorific value almost appears as a straight line but the output specific work as a curve. At the same time, the gas flow and the useful work coefficient decline and the decreased speed of gas flow almost appears as a straight line but the useful coefficient as a curve. Meanwhile, with the rising of $\mathrm{H}_{2}$ content, thermal efficiency of gas turbine and the whole system both increase generally. While the content of $\mathrm{H}_{2}$ increases from $10 \%$ to $70 \%$, the thermal efficiency of integrated system increases from $61.6 \%$ to $64.2 \%$. Above all, it indicates that the rising of $\mathrm{H}_{2}$ content in fuel gas is benefit to the thermal performance and energy produced quantity of the system.

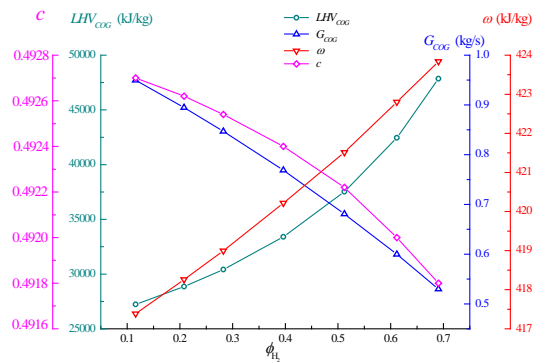

FIGURE IV. EFFECT OF CONTENT OF $\mathrm{H}_{2}$ IN COG ON THE SYSTEM PERFORMANCE.

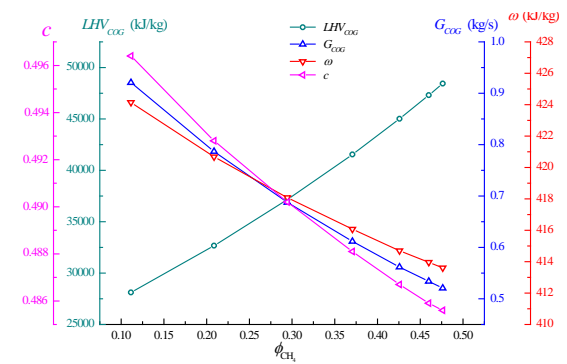

FIGURE V. EFFECT OF CONTENT OF $\mathrm{CH}_{4}$ IN COG ON THE SYSTEM PERFORMANCE.
Figure 5 is the influence of the methane content on system performance. With the rising of $\mathrm{CH}_{4}$ content, the gas flow, output specific work, useful work coefficient and thermal efficiency of gas turbine decrease, but the low calorific value of COG and the thermal efficiency of the whole system increases. Compared with the influence of the $\mathrm{H}_{2}$ content, the effect of $\mathrm{CH}_{4}$ content on the specific work of gas turbine unit and the thermal efficiency are opposite. Considered that $\mathrm{H}_{2}$ and $\mathrm{CH}_{4}$ are both important gas for the gas cycling performance, meanwhile, the gas cycling is the highest energy grade thermal circulation in CCHP system and has important influence on steam cycle and refrigeration cycle. Therefore, it won't consider the influence of $\mathrm{H}_{2}$ and $\mathrm{CH}_{4}$ content on system performance alone but analyze the effect of gas low calorific value on the system performance.

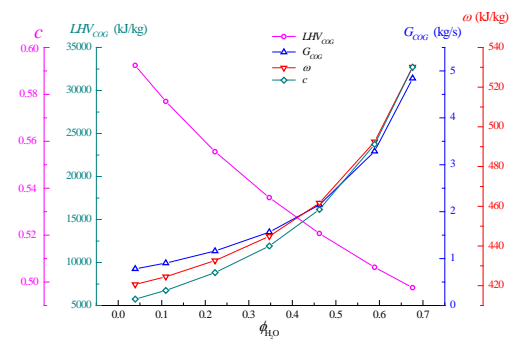

FIGURE VI. EFFECT OF CONTENT OF $\mathrm{H}_{2} \mathrm{O}$ ON THE SYSTEM PERFORMANCE.

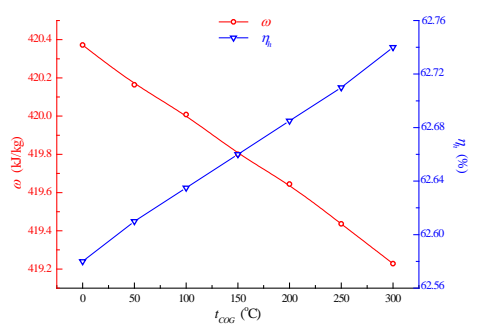

FIGURE VII. EFFECT OF TEMPERATURE OF COG ON THE SYSTEM PERFORMANCE.

Fig.6 is the influence of the water vapor content on system performance. With the rising of $\mathrm{H} 2 \mathrm{O}$ content, the low calorific value of gas decreases gradually. The gas flow rate, output specific work, useful work coefficient of gas turbine and the unit thermal efficiency all increase with the increasing of $\mathrm{H} 2 \mathrm{O}$ content of COG, and the increased speed all goes up. The above analysis shows that the rising of $\mathrm{H} 2 \mathrm{O}$ content is favor to the thermal performance of gas turbine unit. However, for the COG-CCHP integrated system, the thermal efficiency of the integrated system decreases with the water vapor increasing. In the process that the content of $\mathrm{H} 2 \mathrm{O}$ increases from $10 \%$ to $70 \%$, the thermal efficiency of integrated system decreases from $62.6 \%$ to $51.0 \%$. Compared with the same amplitude of $\mathrm{H} 2$ and $\mathrm{CH} 4$ content, the content of $\mathrm{H} 2 \mathrm{O}$ affects more obviously on system performance, and this explains that the sensitivity for the content of H2O on COG-CCHP integrated system is high. Therefore it should be considered in actual process.

With the discussing of the influence on system performance from the COG main composition above, then it analyzes the influence of COG thermal parameters on system 
thermal performance and energy consumption. Figure 12 is the influence of COG temperature on system performance. With the rising of gas temperature, the output specific work and the thermal efficiency of gas turbine unit decrease, but the decreasing amplitude is small and it can be ignored in actual process. And the thermal efficiency of integrated system goes up but only has small amplitude. When the gas temperature increase from $0{ }^{\circ} \mathrm{C}$ to $300{ }^{\circ} \mathrm{C}$, the thermal efficiency of integrated system increases about $0.2 \%$. Therefore, the influence of the gas temperature on system is small.

\section{SUMMARY}

It obtains the relevant conclusions based on modeling, calculating and analyzing the combined cooling heating and power system driven by the coke oven gas:

With the increase of the temperature ratio, the system thermal efficiency increase, inversely, with the increase of the pressure ratio, the system efficiency decrease. When the temperature ratio gains from 4.20to 4.66, the thermal efficiency increases from $57.5 \%$ to $61.5 \%$ with the pressure ratio fixed at16.0. However, when the pressure ratio gains from 6 to 18 , the thermal efficiency decreases from $62.85 \%$ to $61.5 \%$ with the temperature ratio fixed at 4.20.

The content of $\mathrm{H}_{2}$ in COG has a favor to the thermal performance and energy production of the whole system. While the content of $\mathrm{H}_{2}$ increases from $1 \%$ to $70 \%$, the thermal efficiency of integrated system increases from $61.6 \%$ to $64.2 \%$. Compared with the influence of the $\mathrm{H}_{2}$ content, the effect of $\mathrm{CH}_{4}$ content on the specific work of gas turbine unit and the thermal efficiency is opposite. Above all, it indicates that the rising of $\mathrm{H}_{2}$ content in fuel gas is benefit to the thermal performance and energy produced quantity of the system.

The gas flow, output specific work, useful work coefficient and the thermal efficiency of the unit are all increase with the gaining of $\mathrm{H}_{2} \mathrm{O}$ content, and the increasing speed accelerate with the growth of $\mathrm{H}_{2} \mathrm{O}$ content. The content of $\mathrm{H}_{2} \mathrm{O}$ has an obvious influence for the overall performance of the system and this explains that the COG-CCHP integrated system is sensitive to the content of $\mathrm{H}_{2} \mathrm{O}$.

\section{ACKNOWLEDGMENTS}

The Project Supported by National Natural Science Foundation of China No. 51274224.

\section{REFERENCES}

[1] M Modesto, S A Nebra. Exergoeconomic analysis of the power generation system using blast furnace and coke oven gas in a Brazilian steel mill. Applied Thermal Engineering, 2009, 29: 2127-2136.

[2] Wei Han, Hongguang Jin, Rumou Lin. A novel power generation system based on moderate conversion of chemical energy of coal and natural gas. Fuel, 2011, 90: 263-271.

[3] C Z Li, Y M Shi, X H Huang. Sensitivity analysis of energy demands on performance of CCHP system. Energy Conversion and Management, 2008, 49: 3491-3497.

[4] Jianzhong Xu, Jun Sui, Bingyu Li, et al. Research, development and the prospect of combined cooling, heating, and power systems. Energy, 2010, 35: 4361-4367.

[5] Pedro J Vourliotakis, Anna K Hueffed. Evaluation of a turbine driven CCHP system for large office buildings under different operating strategies. Energy and Buildings, 2010, 42: 1628-1636.
[6] A. Smith, R. Luck, P. J. Mago. Analysis of a combined cooling, heating, and power system model under different operating strategies with input and model data uncertainty. Energy and Buildings, 2010, 42: 2231-2240.

[7] S.K. Chou, W.M. Yang, K.J. Chua, et al. Development of micro power generators - A review. Applied Energy, 2011, 88: 1-16.

[8] Aaron Smith, Rogelio Luck, Pedro J Mago. Analysis of a combined cooling, heating, and power system model under different operating strategies with input and model data uncertainty. Energy and Buildings, 2010, 42: 2231-2240

[9] Hongbin Zhao, Pengxiu Yue. Study of humid air turbine cycle with external heat source for air humidification. Energy Research, 2010, 34: 523-534. 